
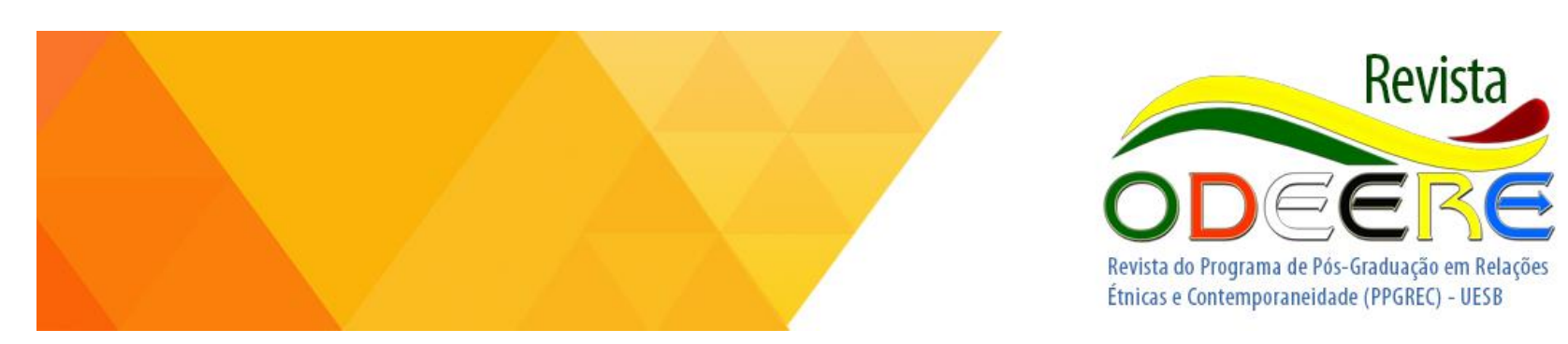

\title{
Dialética dos
}

conceitos em

Gilberto Freyre -

Casa-Grande \&

Senzala: o devir da democracia racial

\author{
Antônio Charles Santiago \\ Almeida \\ Universidade Estadual do \\ Paraná (UNESPAR) \\ sandiabo@yahoo.com.br
}

\section{Resumo:}

Gilberto Freyre, autor de Casa-Grande \& Senzala, pensador polêmico, mas singular no que se propõe - tradução da realidade brasileira à luz da miscigenação. Pode se dizer que nos textos desse recifense existem mais do que contradições, são, no sentido de determinados conceitos, debates dialéticos. Desse modo, o artigo aqui proposto intenta pensar o termo democracia racial por meio de um procedimento filosófico, a saber, dialética conceitual. Assim, não se pretende fazer uma defesa do autor em questão, mas para além disso, observar $\mathrm{o}$ debate $\mathrm{e}$ contribuir para novos entendimentos em torno desse polissêmico conceito. Sendo assim, o texto encontra-se dividido em dois momentos, no primeiro momento, busca-se um diálogo com os estudiosos do pensamento de Gilberto Freyre para localização e compreensão histórica de seu expediente teórico e, no segundo momento, atina-se para uma observação filosófica do conceito de dialética.

Palavras-chave: Mestiçagem. Democracia. Dialética.

\begin{abstract}
:
Gilberto Freyre, author of Casa-Grande \& Senzala, was a controversial thinker; but he was also exceptional at what he aimed, which was the translation of Brazilian reality in light of miscegenation. It can be said that in the texts of this author, born in Recife, there is
\end{abstract}


more than contradictions; they are, in the sense of some concepts, dialectic discussions. In this article we intend to reflect on the term racial democracy in light of a philosophical procedure: dialectics of concepts. Thus, there is no intention of presenting a defense for the author in question, but beyond that, examining the discussion and contributing to new understandings of that polysemic concept. The text is divided in two moments: firstly, we seek to set up a dialogue with scholars of Gilberto Freyre's thinking, in order to get to the localization and historical comprehension of his theoretical asset; in the sequence, we examine the philosophical foundation of the concept of dialectics.

Key-words: Miscegenation. Democracy. Dialectics.

\section{Gilberto Freyre: um escritor perene ${ }^{1}$}

Adorno juntamente com Horkheimer, no texto dialética do esclarecimento, refazem o percurso kantiano, o que é o esclarecimento, para criticar o modelo contemporâneo de racionalidade instrumental. Nas palavras desses autores, "mas, completamente iluminada, a terra resplandece sob o signo do infortúnio triunfal. O programa do iluminismo era o de livrar o mundo do feitiço ${ }^{2 \prime \prime}$.

Os autores mencionados, na assertiva acima, reclamam da dialética uma outra compreensão, mais precisamente, buscam a antítese do esclarecimento que, não necessariamente, significa a escuridão, pelo contrário, mas observam o esclarecimento de um outro ponto, usam lentes diferenciadas na leitura do esclarecimento, um procedimento dialético. Na sequência da assertiva, os autores não só fazem críticas ao modelo de esclarecimento, como na esteira da dialética, observam a importância do conceito para a modernidade, a emancipação dos não esclarecidos.

Pois bem, a expressão democracia racial é, de algum modo, provocadora de arrepios, sobretudo quando é utilizada para traduzir a realidade brasileira, diga-se de passagem, uma

\footnotetext{
${ }^{1}$ Na obra Como e porque sou e não sou sociólogo, Gilberto Freyre no prefácio faz a constatação de que antes mesmo de sociólogo ou antropólogo ele é, mais do que tudo, escritor. Uma leitura indispensável para compreensão desse autor, pois a obra funciona como uma autobiografia, onde o autor busca explicar boa parte dos seus textos. Nas palavras desse autor (1968, p.23) "não sou nem pretendo ser sociólogo puro. Mais do que ser sociólogo creio ser antropólogo. Também me considero um tanto historiador e, até, um pouco pensador. Mas o que principalmente sou creio que é escritor".

${ }^{2}$ ADORNO, Theodor W; HORKHEIMER, Max. Dialética do Esclarecimento. Rio de Janeiro: Zahar Editores, 1996, p.16.
} 
realidade complexa, marcada pelo preconceito, pela exclusão racial e pelo discurso hierárquico entre raças ${ }^{3}$. Desse modo, não há, nos dias atuais, espaço para confabulações em torno da conceituação de democracia racial. Todavia, do ponto de vista dialético, compete refazer o conceito ou, pelo menos, provocar novos debates em torno dessa temática.

Gilberto Freyre, na obra Casa-grande \& Senzala, promove uma compreensão do Brasil, que se distancia nos anos trinta do que se era produzido nos anos vinte, no mundo e de alguma maneira se reproduzia no Brasil. Basta mencionar os movimentos eugenistas, dos quais se pode destacar o I Congresso Brasileiro de Eugenia que aconteceu em julho de 1929, no Rio de Janeiro.

Grosso modo, os anos vinte no Brasil, havia um sentimento de que o país não podia, com seu grau de miscigenação devido a sua matriz étnica, atingir elevados graus de grandeza, nobreza e de progresso uma vez que o tipo de homem brasileiro era um ser misturado, mais precisamente, um mestiço.

Ricardo Benzaquen de Araújo (1994), na obra Guerra e Paz, refere-se a duas posições teóricas que aconteciam nos anos 20 , mais especificamente, aponta duas maneiras de se pensar na questão da miscigenação; a primeira derivada da influência de Gobineau, para esse autor, a presença do negro inviabilizava o desenvolvimento do país, pois a raça mestiça depravava os ideais de civilização. E a segunda posição, na contramão da primeira, buscava o branqueamento, acreditava no progresso do país, mas, a longo prazo, era preciso branquear o país, erradicar a presença do negro da realidade brasileira.

Decerto que a miscigenação, ainda segundo Ricardo Benzaquen de Araujo (1994), do ponto de vista do entendimento conceitual, era pecha, sinônimo de deficiência e de atraso. A produção sociológica dos anos trinta, articulada nos escritos de Gilberto Freyre, ressignifica o termo miscigenação e o qualifica com os adornos da cultura, ou seja, a mestiçagem é um polo de cultura. E, Casa-grande \& Senzala, sem dúvida alguma, é vanguarda desse procedimento inovador, miscigenar pela cultura. Na obra Gilberto Freyre, uma biografia cultural, os autores Larreta e Giucci fazem a seguinte narrativa, referindo-se a obra Casa-grande \& Senzala:

[...] fundamental não só porque supõe a inversão de uma tradição que via no negro uma das causas do fracasso do Brasil, como porque, na revalorização da

\footnotetext{
${ }^{3}$ Esta questão pode ser observada de como a população de um modo muito geral lida com as políticas afirmativas. Quando se trata de ações afirmativas é muito comum a falta de compreensão, bem como de um bom debate, pautado em conteúdo, em dados e, acima de tudo, em coerência com os fatos.
} 
contribuição do negro para a cultura brasileira, apoia-se na distinção teórica raça/cultura, que constitui o arcabouço de Casa-grande \& Senzala ${ }^{4}$.

De acordo com a citação apresentada, pode-se perceber como a obra de Gilberto Freyre faz a inversão da raça pela cultura e, ainda ressignifica o debate em torno do negro e sua contribuição para formação do Brasil.

É fato que nos anos trinta, recheados de preconceito com o negro, tempos marcados por congressos eugenistas, a posição teórica e, de algum modo, política do recifense, a partir do final dos anos vinte, é uma afronta aos intelectuais de seu tempo, bem como a forma importada de se fazer ciências sociais no Brasil. Vamireh Chacon, na obra Gilberto Freyre uma biografia intelectual, apresenta como a escrita da obra Casa-grande \& Senzala, juntamente com a Primeira Semana Afro-brasileira, ocorrida em 1934, na cidade do Recife, projetou Gilberto Freyre como o inimigo das elites pernambucanas em razão de sua postura de defesa e de enaltecimento da mestiçagem. Nas palavras de Chacon:

[...] em Pernambuco desabará contra Gilberto Freyre - discípulos e amigos violenta repressão inclusive policial, com prisões e torturas principalmente contra Gilberto Freyre e seu primo o psiquiatra Ulysses Pernambucano, durante a ditadura parafacista de Getúlio Vargas, o Estado Novo de 1937 a $1945^{5}$.

O Gilberto Freyre aqui apresentado difere e muito do recifense que é apresentado na obra de Pallares-Burke, Gilberto Freyre - um vitoriano dos trópicos, mais precisamente nos anos vinte, no seu período de passagem nos Estados Unidos, em que não havia por parte desse recifense uma postura definida e enérgica para com a questão afrodescendente, afirma PallaresBurke. Ainda de acordo com essa estudiosa, São vários os fatores que contribuem para essa mudança de perspectiva, aqui compreendida como defesa de uma causa, a substituição da noção de raça pela noção de cultura, cujo objetivo era, dentre outras coisas, positivar a leitura da miscigenação. Basta recordar as teses aqui já apresentadas por Ricardo Benzaquen de Araújo (1994).

Em Gilberto Freyre, nos anos trinta, observa-se uma rearticulação do debate em torno da miscigenação e tem-se uma nova compreensão de realidade brasileira, a colonização nos trópicos

\footnotetext{
${ }^{4}$ LARRETA, Enrique Rodríguez. GIUCCI, Guillermo. Gilberto Freyre - uma biografia cultural. Rio de Janeiro: Civilização Brasileira, 2007, p.443.

${ }^{5}$ CHACON, Vamireh. Gilberto Freyre - uma biografia intelectual. São Paulo: Ed. Nacional, 1993, p.121.
} 
favoreceu a tipologia de um novo homem, o miscigenado brasileiro. E esta observação é, diretamente, influenciada pelo antropólogo Franz Boas. Nas palavras de Gilberto Freyre:

[...] foi o estudo de antropologia sob a orientação do professor Boas que primeiro me revelou o negro e o mulato no seu justo valor - separados dos traços de raça os efeitos do ambiente ou da experiência cultural. Aprendi a considerar fundamental a diferença raça e cultura $[. . .]^{6}$

É sabido que, no entendimento de Palarres-Burke, Gilberto Freyre, antes da escrita da obra Casa-Grande \& Senzala no período que passou nos Estados Unidos, pouco se envolveu com a questão do negro, parecia indiferente, sobretudo, com as reflexões e militância de seu professor de antropologia Franz Boas. E ainda, de acordo com a autora mencionada, existem, no cotidiano de Gilberto Freyre até meados dos anos vinte, elementos que o classifica como racista. Para Palarres-Burke,

[...] há alguns indícios, aqui e acolá, de que, de um lado, o paradigma racista norteava algumas de suas observações e, de outro, que ele estava penosamente tentando se definir em face das múltiplas e contraditórias referências, leituras e experiências que lhes povoavam a mente ${ }^{7}$.

Todavia, essa não pode ser uma compreensão reducionista, pois na esteira do que apresenta a assertiva, tem-se um Gilberto Freyre que assume como projeto vital, a ressignificação do debate em torno da miscigenação e, ainda, de valorização e potencialização da cultura negra, com forte influência de seu professor Boas, já apresentado acima quando Gilberto Freyre relata a importância desse antropólogo na sua condução desse nova perspectiva, ressignificar a cultura brasileira à luz da potencialização da mestiçagem.

A questão a considerar nesse debate é como a perspectiva muda e muito, quer dizer, tem-se um Gilberto escrevendo no início dos anos vinte e um outro Gilberto escrevendo no final dos anos vinte e início dos anos trinta, é como se existisse uma fratura entre o escritor dos anos vinte, indiferente à questão da miscigenação e o antropólogo do final dos anos vinte, o herdeiro da antropologia de Franz Boas.

Essa dicotomia entre os anos vinte e trinta na vida intelectual e militante de Gilberto Freyre é provocadora de polêmicas, pois quase sempre, algumas leituras em torno desse autor, tomadas fora desse contexto histórico, geram ambivalência e prejuízo na compreensão do

\footnotetext{
${ }^{6}$ FREYRE, Gilberto. Casa-Grande \& senzala. São Paulo: Global Editora, 2006, p.32.

${ }^{7}$ PALLARES-BURKE, Maria Lúcia Garcia. Gilberto Freyre - um vitoriano dos trópicos. São Paulo: Unesp, 2005, p.309.
} 
seu corpo teórico, quer dizer, uma compreensão dos textos dos anos vinte como uma leitura totalizante de todo o seu arcabouço teórico.

É sabido como já foi apresentado que Gilberto Freyre é um grande intelectual e que teve uma produção teórica gigantesca e dentro dessa produção se tem mudanças de perspectivas bem como, provavelmente, fragilidades no corpo dessa produção que acabam, certamente, provocando esses debates. Veja que Clovis Moura na obra sociologia do negro brasileiro conclui deliberadamente que a obra Casa-grande \& senzala faz parte de um projeto, cujo objetivo é mascarar a existência do escravismo brasileiro.

[...] o mito do bom senhor de Freyre é uma tentativa sistemática e deliberadamente bem montada e inteligentemente arquitetada para interpretar as contradições estruturais do escravismo como simples episódio epidérmico, sem importância, e que não chegaram a desmentir a existência dessa harmonia entre exploradores e explorados durante aquele período ${ }^{8}$.

Clovis Moura é, sem dúvida alguma, intelectual que representa a sociologia brasileira, mas exagerou quando ponderou sobre o livro Casa-grande \& senzala, uma vez que o objetivo da obra, dentre outras coisas, representava nos anos trinta a tradução da realidade brasileira, ou seja, existia um grupo de intelectuais que, invariavelmente, buscava ressignificar a forma de se fazer sociologia no Brasil, mais precisamente, reconfigurar os conceitos que empalmavam a realidade brasileira. Desse modo, assegura Gilberto Freyre no seu livro Como porque sou e não sou sociólogo, "daí ser Casa-Grande \& senzala um livro múltiplo em suas perspectivas; contraditório, até, no seu perspectivismo; passível da acusação de negrófilo"”.

Benzaquen, autor aqui já mencionado anteriormente, na obra Guerra e Paz faz considerações significativas com relação ao mito do bom senhor, discussão apontada por Clóvis moura na obra sociologia do negro brasileiro. Para Benzaquen, chega a ser difícil de se fazer esse tipo de leitura, por mais que pareça verdadeiro, pois a obra Casa-grande \& senzala é um corpo recheado de violência, de crueldade e, claro, de flexibilidade. Por isso, Benzaquen reclama um debate mais apurado, mais atento. Nas palavras desse autor, referindo-se Casa-grande \& senzala:

\footnotetext{
${ }^{8}$ (1988, p. 18) MORA, Clóvis. Sociologia do Negro Brasileiro. São Paulo: editora Ática, 1988, p.18

9 (1968, p. 117) FREYRE, Gilberto. Como e porque sou e não sou sociólogo. Brasília: Universidade de Brasília, 1968 p.117.
} 
[...] assim, desde o prefácio, onde nos deparamos com 'senhores mandando queimar vivas, em fornalhas de engenho, escravas prenhas, as crianças estourando ao calor das chamas' [...], até a denúncia, algo mais sutil, de um outro tipo de violência, a 'sifilização do Brasil', realizada essencialmente pelos portugueses e acusada praticamente em quase todo o texto [...], podemos perceber que, apesar da mestiçagem, da tolerância e da flexibilidade, o inferno parecia conviver muito bem com o paraíso em nossa experiência colonia $\left.\right|^{10}$.

Dito anteriormente, não se pretende tomar uma posição em relação ao debate que circunscreve o pensamento de Gilberto Freyre, mas antes disso, busca-se à luz da dialética conceitual pensar ou repensar o conceito de democracia racial no expediente desse autor. Desse modo, para facilitar a compreensão do debate, optou-se por essa breve apresentação e diálogo com os estudiosos do pensamento do autor de Casa-grande \& senzala.

\section{Democracia racial - incipiência filosófica}

Democracia, mais do que governo do povo, uma falácia conceitual advinda do grego antigo. Sem adentrar nesse debate, compete pensar conceitualmente nesse poder do povo, nessa igualdade entre os homens, como prevê o estatuto da democracia. Pois bem, de posse dessa compreensão de igualdade entre os homens é que se pode pensar, especificamente no Brasil, a incipiência da democracia brasileira.

Não é de se assustar que, recentemente, uma população jovem, nas ruas dos grandes centros, solicitava uma intervenção militar como resolução dos problemas sociais e políticos brasileiros. Foi possível perceber nessa ação de massa, uma incompreensão no que diz respeito ao debate em torno da democracia e seu papel político, haja vista que no entendimento de uma parcela significativa da juventude, a ditadura militar poderia suplantar o procedimento democrático e sanar os problemas que afligem a política brasileira. Desse modo, pode-se objetar que a concepção de democracia não tem raízes sólidas na cultura brasileira. Assim, no trabalho em curso, compete perguntar - quais são os impedimentos para que se tenha, na cultura brasileira, solidez na compreensão da democracia?

As respostas são as mais variadas possíveis, entretanto, aqui se faz menção há duas. A primeira resposta para alguns é a falta de educação política, pois boa parte da população brasileira

\footnotetext{
${ }^{10}$ (1994, p.48) ARAUJO, Ricardo Benzaquen. Guerra e paz - Casa-grande \& senzala e a obra de Gilberto Freyre nos anos 30. Rio de Janeiro: Editora 34, 1994.
} 
não dispõe de um entendimento da vida pública, pelo contrário, não só compreende o movimento da vida privada, como reduz a sua ação cotidiana à dimensão do privatismo - 'o eu e o mercado de trabalho" e, por isso, quando emite uma opinião a respeito da política ou da vida pública é sempre uma posição pautada nos seus interesses pessoais. Já para outros, nesse segundo entendimento, a política brasileira, especificamente os políticos brasileiros, na sua maioria absoluta, não permitem qualquer sentimento de crença no processo político e nesse conjunto de entendimento, política é sinônimo de corrupção, de malandragem.

Decerto que o Brasil, na sua contemporaneidade, transformou a política no sentido lato, no locus da pessoalidade, da religiosidade e do privatismo. Não é de se admirar que as casas legislativas têm dado provas nas suas ordinárias seções de que se assemelham e muito com os templos religiosos, onde as palavras de ordem são, quase sempre, Deus e família. Não cabe estender o debate, mas é certo que democracia é, na cultura brasileira, para boa parte da população, uma expressão politiqueira. E se não há espaço para o enraizamento da democracia na cultura, o que há de se dizer na cultura brasileira da democracia racial?

Não é difícil de responder à questão, pois na prática não há democracia racial no Brasil, o que há é um grande engodo. Basta perceber que existe um grande fosso que separa o branco do negro e tamanha separação se faz em razão de uma hierarquia social. Os índices atestam a diferença no mais auto escalão dos setores públicos e privados, a diferença nos postos de trabalho, nas universidades públicas, na vida política. Os dados são alarmantes. Desse modo, do ponto de vista prático e categórico, não há democracia racial, brancos e negros são diferentes, não do ponto de vista raça/cultura, mas, inclusive, do ponto de vista do direito, um direito de branco. Todavia, como se não bastasse a crueldade dos dados, na vida prática tem-se enraizado na cultura brasileira, o discurso da classificação racial hierárquica, isto é, veladamente, acredita-se na inferioridade do negro frente ao branco com relação ao intelecto ${ }^{11}$ e ao estético ${ }^{12}$. A comprovação da crença se faz sentir no mundo das artes, das telenovelas, indústria da moda etc....

\footnotetext{
${ }^{11}$ O ódio de raça, estampado na crítica as políticas afirmativas, ostenta o discurso hierárquico da inferioridade do negro, quando, desprovido de dados científicos, afirmam o empobrecimento das instituições públicas com a presença dos cotistas.

${ }^{12}$ Aqui cabe uma observação cotidiana que se faz sentir no recorte entre as regiões brasileiras. 0 senso comum, desprovido de qualquer sentimento estético, ostenta, na região sul do país, que a beleza, sobretudo feminina, encontra-se nessa região, pois se verifica na cor dos olhos, na cor da pele, no fio dos cabeços, traços singulares que se diferenciam e muito de outras regiões. No fundo, a ostentação é de colonização, quer dizer, onde se localizou o europeu e quais foram os mecanismos de barragem que estas regiões criaram para extirpar o negro em detrimento da
} 
É certo que não há democracia racial, não há o que se discutir com relação às práticas de racismo e de preconceitos velados, mas que subsistem na consciência coletiva de grande parte da população brasileira. Contudo, a prática do racismo, do preconceito, da exclusão e da marginalização do negro no Brasil, não pode significar, de maneira nenhuma, vetores para leituras descontextualizadas de uma obra de grande envergadura no Brasil e no mundo como Casa-grande \& senzala. Os autores Larreta e Giucci, na obra Gilberto Freyre - uma biografia cultural, trazem à tona uma escrita do intelectual Mexicano Afonso Reis que, dentre outras coisas, foi embaixador do México no Brasil no período de 1930 a 1936, faz referência à obra de Gilberto Freyre, CasaGrande \& senzala, "meu querido Gilberto Freyre. Seu livro é uma maravilha de matéria, de construção e de espírito. Conforme avanço em sua leitura, tenho a impressão de ir segurando o Brasil pelo próprio cordão umbilical ${ }^{13 \prime \prime}$.

No que corresponde à dialética, aqui compreendida à luz do hegeliano/marxismo filosóficos, o conceito de democracia racial, exposta no pensamento de Gilberto Freyre, traz consigo uma ideia, mas que na práxis se distancia gerando um conflito tese/antítese. Porém, ainda do ponto de vista dialético, na busca pela síntese, espera-se o autor Gilberto Freyre, na construção conceitual, ressignificar a tese para que a síntese/tese possa reconstruir não só o debate da miscigenação, mas potencializar a práxis na construção de uma nova identidade brasileira a partir da pluralidade cultural do branco/índio/negro.

O conceito aqui apresentado, democracia racial, é, no pensamento de Gilberto Freyre, mais do que uma constatação de uma realidade brasileira, entendida por boa parte de seus leitores e críticos, estende-se ao dever-ser, a ressignificação da tese/negatividade miscigenação numa relação direta com a antítese/positividade gilbertiana. Por essa razão, o debate conceitual aqui proposto, é filosófico, busca os princípios da dialética para, a partir disso, pensar numa democracia racial como perspectiva que não se reduz ao fato em si, o momento histórico, mas no sentido dialético hegeliano, faz-se em razão da ideia universal, o vir-a-ser, nas palavras de Gilberto Freyre, apresentadas na abertura da obra Casa-grande \& senzala, publicada pela editora global:

\section{Eu ouço as vozes}

\footnotetext{
valorização do branco e do ideal de branqueamento brasileiro. E nunca é demais sustentar que se trata de um discurso, apenas uma posição preconceituoso e de raça.

${ }^{13}$ LARRETA, Enrique Rodríguez. GIUCCI, Guillermo. Gilberto Freyre - uma biografia cultural. Rio de Janeiro: Civilização Brasileira, 2007, p.437.
} 


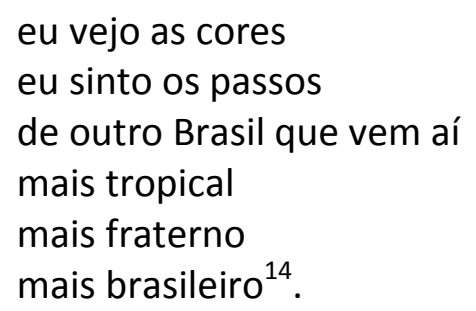

A democracia racial é, nesse entendimento gilbertiano, um aceno para novas relações, relações de um dever-ser brasileiro. E esse dever-ser configura-se como síntese/tese de uma leitura antropológica de Franz Boas em antítese à compreensão de Gobineau e seus seguidores no Brasil. Por isso, a democracia racial, conceito caro ao pensamento de Gilberto Freyre, pode contribuir para novas perspectivas políticas, pois o aceno não é de uma defesa no sentido de que existe democracia racial, mas de um porvir, deve acontecer, uma vez que miscigenação é, nesse contexto, o retrato positivo do Brasil.

José Carlos Reis, na obra As Identidades do Brasil, diz que a avaliação positiva da miscigenação representou uma espécie de alívio para as elites brasileiras, pois nas palavras desse autor, "ele Ihes devolveu a autoconfiança que as teorias racistas do final do século XIX Ihes tinham tirado". [...] Desde 1822, as elites brasileiras esforçavam-se por esconder dos estrangeiros e de si mesmas a 'impureza' da história nacional ${ }^{15 \prime \prime}$. Decerto que o historiador José Carlos Reis faz um diagnóstico do pensamento gilbertiano e o denomina de leitura conservadora, mas não deixa de apresentar as contribuições que são visíveis de Gilberto Freyre para a construção de uma identidade nacional. E de forma específica, há uma ressignificação do debate miscigenação, uma vez que, à luz de Gilberto Freyre, diz José Carlos Reis (2007), com o pensamento gilbertiano há uma identificação das elites brasileiras com a história nacional, já que esta era motivo de vergonha para boa parte da elite brasileira.

\section{Á guisa de uma conclusão}

O artigo aqui apresentado é resultado de estudos que vêm acontecendo no Laboratório Gilberto Freyre, pertencente ao Colegiado de Filosofia da Universidade Estadual do Paraná -

\footnotetext{
${ }^{14}$ FREYRE, Gilberto. Casa-Grande \& senzala. São Paulo: Global Editora, 2006.

15 REIS, José Carlos. As identidades do Brasil. De Varnhagem a FHC. Rio de Janeiro: Fundação Getúlio Vargas Editora, 2005, p.69.
} 
Unespar, Campus de União da Vitória. É sabido que Gilberto Freyre é, dentre muitos autores brasileiros, provocador de polêmicas, mais precisamente suas obras, como sua vida de intelectual e político promovem intensos e tensos debates. A leitura que se pretendeu não atinou para uma defesa desse autor, mais antes disso buscou a partir de consagrados estudiosos do pensamento gilbertiano, repensar a circunstância em que se encontrava Gilberto Freyre e o objetivo de sua obra, construção de uma identidade nacional. E dentro desse contexto, o artigo versou sobre o conceito de democracia racial, não como um conceito existente, um ser no mundo, mas um porvir, o dever-ser conceitual.

Desse modo, longe de fazer a defesa de um Brasil racialmente democrático, pode-se, à luz de Gilberto Freyre, refazer o debate e defender a democracia racial como elemento vital de um país mestiço. A tese é de que não existe democracia racial. A antítese deve negar a tese, aqui não quer dizer que a negação seja, na práxis, o ser-em-si, mas o dever-ser como condição de síntese/tese, uma espécie de movimento constante.

Por essa razão, longe de esgotar o tema, buscou-se uma leitura de Gilberto Freyre para refazer o debate em torno da democracia racial, não como entendida, isto é, uma farsa de mascaramento do racismo e sim como perspectiva, o vir-a-ser dialético.

\section{Bibliografia}

ADORNO, Theodor W; HORKHEIMER, Max. Dialética do Esclarecimento. Rio de Janeiro: Zahar Editores, 1996.

ARAUJO, Ricardo Benzaquen. Guerra e Paz - Casa-grande \& senzala e a obra de Gilberto Freyre nos anos 30. Rio de Janeiro: Editora 34, 1994.

CHACON, Vamireh. Gilberto Freyre - uma biografia intelectual. São Paulo: Ed. Nacional, 1993.

FREYRE, Gilberto. Casa-Grande \& senzala. São Paulo: Global Editora, 2006.

Como e porque sou e não sou sociólogo. Brasília: Universidade de Brasília, 1968.

LARRETA, Enrique Rodríguez. GIUCCI, Guillermo. Gilberto Freyre - uma biografia cultural. Rio de Janeiro: Civilização Brasileira, 2007

MORA, Clóvis. Sociologia do Negro Brasileiro. São Paulo: editora Ática, 1988

PALLARES-BURKE, Maria Lúcia Garcia. Gilberto Freyre - um vitoriano dos trópicos. São Paulo: Unesp, 2005. 
REIS, José Carlos. As identidades do Brasil. De Varnhagem a FHC. Rio de Janeiro: Fundação Getúlio Vargas Editora, 2005.

Antônio Charles Santiago Almeida: graduado em Filosofia pela Universidade Estadual de Santa Cruz - UESC (2004), Especialista em Educação, Cultura e Memória pela Universidade Estadual do Sudoeste da Bahia - UESB (2006), Mestre em Ciências Sociais pela Pontifícia Universidade Católica de São Paulo - PUC - SP (2009) e doutor em educação pela Universidade Federal do Paraná - UFPR (2015). É professor adjunto da Universidade Estadual do Paraná - UNESPAR/FAFIUV. Coordenador do subprojeto de Filosofia - Pibid da Universidade Estadual do Paraná. Coordenador do Laboratório Gilberto Freyre e professor do Programa de Mestrado Profissional - PROFILO. Presidente da Comissão de estudo e implantação do Curso de Ciências Sociais da Universidade Estadual do Paraná - UNESPAR

Artigo recebido para publicação em: Outubro de 2016.

Artigo aprovado para publicação em: Dezembro de 2016. 